\title{
Considerações sobre a degradação da fibra em forragens tropicais associada com suplementos energéticos ou nitrogenados
}

\author{
Costa, N. de L. ${ }^{1 @ ;}$; Monteiro, A.L.G. ${ }^{2}$; Silva, A.L.P3; Moraes, A. de ${ }^{2}$; Giostri, A.F. ${ }^{4}$; Stivari, T.S.S. ${ }^{5}$; Gilaverte, S. $^{2}$; \\ Baldissera, T.C. ${ }^{6}$ e Pin, E.A. ${ }^{7}$
}

\begin{abstract}
'Embrapa Roraima. Empresa Brasileira de Pesquisa Agropecuária. Ministério da Agricultura, Pecuária e Abastecimento. Boa Vista. RR. Brasil. ${ }^{2}$ Departamento de Zootecnia. Universidade Federal do Paraná. UFPR. Curitiba. Paraná. Brasil.

3Universidade Tuiuti do Paraná. Curitiba. PR. Brasil.

${ }^{4}$ Centro de Ensino Superior dos Campos Gerais. Ponta Grossa. PR. Brasil.

${ }^{5}$ Faculdade de Medicina Veterinária e Zootecnia da Universidade de São Paulo. USP. SP. Brasil.

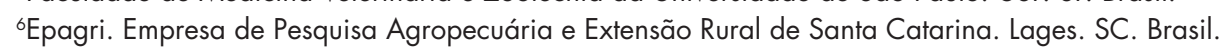

${ }^{7}$ Serviço Nacional de Aprendizagem Rural. Dois Vizinhos. PR. Brasil.
\end{abstract}

\section{PaLAVRAS ChAVE ADICIONAIS}

Carboidrato.

Consumo voluntário.

Proteína bruta.

\section{RESUMO}

Os carboidratos constituem entre 70 e $80 \%$ da dieta dos ruminantes e são fundamentais para o atendimento de suas exigências em energia, síntese de proteína microbiana, componentes do leite e manutenção da saúde animal. As gramíneas forrageiras tropicais apresentam, normalmente, baixos teores de proteína bruta, os quais estão associados a elevados teores de fibra, que pode representar cerca de $60 \%$ da matéria seca consumida. A fibra representa a fração dos carboidratos de digestão lenta ou indigestível do alimento que ocupa espaço no trato gastrintestinal e, em função de sua concentração e digestibilidade, impõe limitações ao consumo voluntário de matéria seca, minerais e energia. A suplementação energética ou protéica pode suprir as necessidades em energia e proteína dos microrganismos e do ruminante, proporcionando condições favoráveis ao ambiente ruminal, maximizando o crescimento microbiano e a utilização dos compostos fibrosos da forragem. A sincronização entre as fontes de carboidratos e as de nitrogênio (N) maximiza a eficiência microbiana e a diminuição da perda de $\mathrm{N}$ em forma de amônia e da energia dos carboidratos, promovendo melhoria na digestão da MS e, especialmente, da fração fibrosa da forragem. Neste artigo são analisados os efeitos da suplementação energética e/ ou protéica sobre a degradação e o consumo da fibra de gramíneas forrageiras tropicais.

\section{Considerations on the fiber degradation of tropical forage associated with energy or nitrogenous supplements}

\section{SUMMARY}

The carbohydrates constitute between 70 and $80 \%$ of ruminant's diet and are fundamental for your demands by energy, synthesis of microbial protein, milk components and maintenance of the animal health. The tropical forage grass present, normally, lower contents of crude protein, which are associated with highest fiber contents that can represent around $60 \%$ of the forage dry matter. The fiber represents the carbohydrate fraction of slow digestion or nondegradable that occupies space in gastrointestinal system and, in function of his concentration and digestibility, imposes limitations to the nutrients voluntary intake, dry matter and energy. The energy or nitrogenous supplements can supply the needs in energy and protein of the microorganisms and of the ruminant, providing favorable conditions to the rumen environment, maximizing the microbial growth and the utilization of the forage fibrous compounds. The synchronization between carbohydrates and protein sources can maximize the microbial efficiency and the diminution of the loss of nitrogen as ammonia and the carbohydrates energy, promoting improvement dry matter digestion, especially forage fibrous fraction. In this paper are analyzed the effects of energy and/or protein supplementation about the degradation and fiber voluntary intake of the tropical forage grasses.

\section{INTRODUÇÃO}

Os ruminantes são reconhecidos por sua capacidade de transformação de alimentos grosseiros, em produtos de alto valor nutritivo, tais como a carne e o leite, através de fermentação microbiana em seu trato gastrintestinal. Os carboidratos constituem entre 70 e $80 \%$ da dieta e são fundamentais para o atendimento das exigências em energia, síntese de proteína microbiana, componentes do leite e manutenção da saúde animal. As características nutritivas dos carboidratos dependem dos açúcares que os compõem e de suas ligações químicas, além de outros fatores de natureza físico-química.

Os carboidratos incluem uma grande variedade de compostos orgânicos que possuem perfis de fer- 
mentação e digestão diferentes, atuando de maneira distinta no organismo animal (Van Soest, 1994). A oxidação da maioria dos carboidratos é a principal via metabólica de liberação de energia, contribuindo com aproximadamente $80 \%$ do total de calorias ingeridas pelos animais. De acordo com o grau de polimerização os carboidratos são classificados em monossacarídeos (um monômero), oligossacarídeos (2-20 monômeros) e polissacarídeos (>20 monômeros). Os carboidratos simples são os monossacarídeos, unidades formadoras das demais classes, constituídos de 3-7 carbonos unidos por ligações covalentes simples e representados principalmente pela glicose e frutose; os oligossacarídeos correspondem aos carboidratos de cadeia curta, unidos por ligações glicolíticas, cujos principais representantes são sacarose e celobiose; os polissacarídeos incluem carboidratos com cadeias superiores representados principalmente pelo amido e pelos polissacarídeos não amiláceos (PNA) que englobam a celulose, hemicelulose e substâncias pépticas (Valadares Filho e Pina, 2006).

Os carboidratos podem ser agrupados em duas grandes categorias conforme seu grau de degradabilidade: estruturais (CE) ou fibrosos $(\mathrm{CF})$ e, não estruturais (CNE) ou não fibrosos (CNF), respectivamente. Os $\mathrm{CF}$ incluem aqueles encontrados normalmente constituindo a parede celular, representados principalmente pela pectina, hemicelulose e celulose, que são normalmente os mais importantes na determinação da qualidade nutritiva das forragens, pois ocupam espaço no trato digestório e exigem mastigação para redução do tamanho de suas partículas e passagem através do sistema digestivo (Van Soest, 1994). Nutricionalmente, os CF e a fibra em detergente neutro (FDN) têm o mesmo significado, pois representam a mesma fração de carboidratos dos alimentos, a qual constitui, em condições tropicais, em média, $60 \%$ da MS total das forragens. Os CNF correspondem aos nutrientes rapidamente fermentados pelos microrganismos ruminais, tais como açúcares solúveis com rápida degradação (glicose, sacarose e amido), além da pectina. A fermentação dos carboidratos no rúmen produz ácidos graxos voláteis que representam a principal fonte de energia para os ruminantes, atendendo até $80 \%$ de seus requerimentos diários, além de maximizarem a síntese de proteína microbiana e a manutenção da função ruminal (Ishler et al., 1996; Varga e Kononoff, 1999).

A fibra representa a fração dos carboidratos de digestão lenta ou indigestível do alimento que ocupa espaço no trato gastrintestinal e, em função de sua concentração e digestibilidade, impõe limitações ao consumo voluntário de matéria seca (MS), minerais e energia. Concentrações mínimas de fibra na dieta que permitam manter a atividade de mastigação e motilidade do rúmen são fundamentais para assegurar uma perfeita saúde dos ruminantes. A excessiva redução nos níveis de fibras nas dietas de ruminantes poderá ser prejudicial à digestibilidade total dos alimentos, visto que a fibra é fundamental para a manutenção das condições ótimas do rúmen, pois altera as proporções de ácidos graxos voláteis, estimula a mastigação e mantém o pH em níveis adequados para a atividade microbiana, que está na faixa entre 6,5 e 6,8 (Romney e Gil, 2000).
As estruturas químicas (composição e proporção entre carboidratos estruturais e concentração de lignina) e físicas (densidade, capacidade de troca de cátions, poder tampão, taxa de digestão, hidratação de partículas e seu tempo de colonização) são as características mais importantes relacionadas à digestibilidade da fibra. Ademais, o rápido e fácil acesso dos microrganismos ruminais à parede celular secundária é fator primordial para potencializar o aproveitamento da fibra pelos ruminantes. O processo de digestão da fibra consiste na hidrólise dos polissacarídeos e a conversão dos monossacarídeos resultantes em ácidos graxos voláteis (AGV), gases da fermentação e calor (Tamminga et al., 1990). A taxa de hidrólise geralmente é o fator limitante na digestão ruminal da fibra (Varga et al., 1998). Esta taxa é limitada pela ação das enzimas no complexo lignina-polissacarídeos, que degradam a parede celular (Chesson e Forsberg, 1988). A extensão da digestão da fibra depende de sua quantidade indigestível e da relação entre a taxa de degradação e a taxa de passagem. A digestibilidade ruminal da fibra de forragens e de outras fontes de alimentos, variam de forma muito ampla, desde 13,5 a 78\% (Varga et al., 1998).

As gramíneas forrageiras tropicais apresentam, normalmente, baixos teores de proteína bruta (PB), os quais invariavelmente estão associados a elevados teores de fibra, em decorrência do processo de espessamento da parede celular e da lignificação de seus tecidos à medida que se tornam mais maduras. Em pastagens de Cynodon nlemfuensis, Oliveira et al. (2013) constataram que a degradabilidade potencial da FDN foi inversamente proporcional à idade das plantas $(83,2 ; 80,3 ; 76,8$ e $75,3 \%$, respectivamente para $28,48,63$ e 79 dias de rebrota). Teores de PB inferiores a $7 \%$ são limitantes a atividade dos microrganismos do rúmen, implicando condições desfavoráveis para o ambiente ruminal, além de comprometerem os limites mínimos para a manutenção do crescimento microbiano e a utilização dos CF da forragem (Lazzarini, 2007; Sampaio et al., 2009). Silva et al. (2014) reportaram que a degradação ruminal da FDN de Andropogon gayanus foi significativamente reduzida com o decréscimo nos teores de PB $(34,6 ; 30,1 ; 28,2$ e $24,2 \%$, respectivamente para teores de PB de 9,6; 7,2, 6,0 e 5,9\%). Neste contexto, há uma baixa degradação da forragem que afeta o aproveitamento da energia potencialmente extraível dos CF da parede celular, resultando em diminuição no consumo de MS e baixo desempenho animal (Paulino et al., 2006). A atividade microbiana ruminal, notadamente sobre os CF depende do nível de nitrogênio (N) e, para forragens de baixa qualidade, a sua deficiência limita a taxa e a extensão de degradação dos CF. A eficiência de utilização dos nutrientes via suplementação energética e/ou protéica surge da necessidade de otimização dos recursos nutricionais basais oriundos de forragens tropicais, as quais constituem os principais recursos nutricionais em sistemas de produção de ruminantes em pastejo. A maximização de utilização desses recursos energéticos pode ser obtida pelo incremento da disponibilidade da porção degradada da FDN, sem que ocorra comprometimento sobre o consumo (Paulino et al., 2006). 
Neste trabalho são revisados os efeitos da suplementação energética e/ou protéica sobre a degradação e o consumo da fibra de gramíneas forrageiras tropicais.

\section{DEGRADAÇÃO DA FIBRA ASSOCIADA COM SUPLE- MENTOS ENERGÉTICOS E/OU NITROGENADOS}

A digestão dos ruminantes envolve constante atividade simbiótica dos microrganismos ruminais com o hospedeiro, que são altamente sensíveis às alterações do meio, afetando não só a extensão da degradação dos componentes dos alimentos, mas também as quantidades e proporções dos produtos resultantes da ação destes. A associação entre composição química e o potencial de degradação dos alimentos determina o maior ou menor crescimento microbiano e produção de ácidos graxos voláteis no rúmen, que são as principais fontes de proteína e energia para bovinos, respectivamente (Church, 1990).

As proteínas e os carboidratos são os nutrientes mais requeridos pelos microrganismos ruminais, os quais maximizam seu crescimento, porém atuam de maneira diferenciada no processo. As proteínas em quantidades adequadas proporcionam o balanço de amônia, peptídeos e aminoácidos e têm maior impacto sobre a eficiência do crescimento microbiano, a qual, em parte, está relacionada à disponibilidade de carboidrato fermentável. Açúcares solúveis e amido são os carboidratos mais intensamente fermentados no rúmen em relação à hemicelulose e celulose. Para maximizar o total de carboidrato fermentado no rúmen é comum reduzir os CF na dieta dos ruminantes e aumentar os de açúcares e amido, contudo, em quantidades elevadas poderão causar disfunção ruminal, decréscimo na taxa de crescimento microbiano e resultar em distúrbios metabólicos. Os efeitos benéficos dos açúcares são decorrentes do rápido aumento no crescimento microbiano causado pelo alto nível de energia prontamente disponível e, maior eficiência de utilização das formas de N solúvel e não-protéico. Exceto para as pentoses (arabinose, ribose e xilose), os demais açúcares causam redução do $\mathrm{pH}$ ruminal no processo de fermentação e resultam em maior quantidade de ácido láctico (Cullen et al., 1986).

\section{SUPLEMENTOS ENERGÉTIICOS}

A suplementação energética é realizada com o objetivo de suprir as exigências em energia, consideradas em pastejo como as mais limitantes ao desempenho animal. Contudo, geralmente ocorrem efeitos associativos negativos, como depressão ou substituição, que dependendo do nível de suplementação, implicam diminuições na digestibilidade da FDN e redução no consumo do volumoso (Paulino et al., 2006). A redução da degradação ruminal da FDN em função da adição de CNF prontamente degradáveis à dieta são, em geral, atribuídos a dois efeitos distintos, denominados efeito $\mathrm{pH}$ e efeito concentrado ou carboidrato (Mould et al., 1983; Arroquy et al., 2004, 2005). No primeiro caso, reduções significativas no pH ruminal são responsáveis pela inibição parcial da degradação da FDN, por comprometerem a condição ideal para o crescimento dos
Tabela I. Cinética da digestão da fibra em detergente neutro do feno de Cynodon dactylon, em função da inclusão de $60 \%$ de amido à dieta (Kinetics of detergent neutral fiber digestion hay of Cynodon dactylon, as affected by inclusion of $60 \%$ starch in the diet).

\begin{tabular}{lccc}
\hline Tratamentos & TC $(\mathrm{h})$ & TD $(\mathrm{h})$ & ED $(\%)$ \\
Sem amido & 1,06 & 0,0630 & 65,3 \\
Com amido & 2,79 & 0,0720 & 61,9 \\
\hline
\end{tabular}

TC= Tempo de colonização (h), TD= Taxa de digestão (h); ED= Extensão do potencial de digestão (\%). Fonte: Mertens e Loften (1980).

microrganismos fibrolíticos (Hoover, 1993; Van Soest, 1994). No segundo caso, atribuem-se como causas a competição por nutrientes essenciais entre microrganismos fibrolíticos e aqueles que degradam os CNF, a qual se pronuncia em meios deficientes em compostos nitrogenados (El-Shazly et al., 1961). Contudo, em pastagens tropicais, a variação do $\mathrm{pH}$ ruminal devido à suplementação da dieta parece ser relativamente pequena, não interferindo no adequado crescimento das bactérias que utilizam carboidratos fibrosos, portanto, nessas condições o efeito carboidrato pode ser considerado o principal responsável pela depressão da digestibilidade da fibra (Detmann et al., 2005; Moraes, 2006).

A disponibilidade de carboidratos solúveis pode deprimir a digestão da fibra sem afetar o $\mathrm{pH}$ ruminal e esse quadro parece ser reflexo da alta efetividade das fibras longas que asseguram a manutenção das condições ruminais, as quais atuam de forma intensa na estimulação do tamponamento ruminal via atividade mastigatória e liberação de saliva (Rooke et al., 1987; Huhtanen, 1987; Mertens, 1994; 1997). Mertens e Loften (1980) concluíram que a redução na degradação da FDN do feno de Cynodon dactylon foi diretamente proporcional à adição de amido, a qual implicou em maior tempo para a colonização das partículas do alimento pelos microrganismos ruminais (tabela I). Apesar de não ter sido observado efeito significativo sobre a taxa de digestão, a extensão do potencial de digestão foi negativamente afetada, decrescendo de 65,3 para $61,8 \%$, respectivamente para 0 e $80 \%$ de amido. Grant (1994) avaliando a cinética da digestão da FDN de dietas à base de feno de Bromus inermis (7,9\% de PB), suplementadas com $55 \%$ de amido puro, reportou reduções extremamente elevadas no $\mathrm{pH}$ ruminal, taxa de digestão e extensão do potencial de digestão (tabela I). A inclusão de níveis crescentes de grãos de milho (20; 40; 60 e $80 \%$ ) em dietas à base de feno de Festuca arundinacea (13\% de PB e $66 \%$ de FDN) resultou em decréscimos significativos no tempo de colonização, taxa de passagem, extensão do potencial de digestão, taxa de digestão e extensão aparente da digestão da FDN (Miller e Muntifering, 1985). Em dietas à base de silagem de milho $(4,89$ de PB; $73,46 \%$ de FDN; $42,56 \%$ e FDA e $8,13 \%$ de lignina), a digestão dos CNF, CF, MS e nutrientes digestíveis totais (NDT) estimados foram positivamente afetadas pelas proporções de grãos, sendo as maiores taxas obtidas com a inclusão de 45 a $60 \%$ de grãos (tabela II). Da mesma forma, Silva et al. (2007), após trabalhar com bovinos consumindo feno de Cynodon spp. 'Tifton 85 ' (4,87\% de PB e $84,56 \%$ de FDN) constataram que a inclusão de 4,3\% de amido na dieta implicou 
Tabela II. Taxas de digestão $\left(\mathrm{h}^{-1}\right)$ dos carboidratos não-fibrosos, carboidratos fibrosos, matéria seca e nutrientes digestíveis totais estimados de silagens de milho, em função da proporção de grãos (Digestion rate $\left(\mathrm{h}^{-1}\right)$ of non-fiber carbohydrate, fiber carbohydrate, dry matter (DM) and total digestible nutrients estimated of corn silage, as affected by corn grains proportions).

\begin{tabular}{lccccc}
\hline Parâmetros & \multicolumn{5}{c}{ Níveis de grãos de milho (\%) } \\
\cline { 2 - 6 } & 0 & 15 & 30 & 45 & 80 \\
\hline Carboidratos não-fibrosos & 0,0803 & 0,2075 & 0,2662 & 0,2556 & 0,2315 \\
Carboidratos fibrosos & 0,0254 & 0,0305 & 0,0304 & 0,0291 & 0,0315 \\
Matéria seca & 62,19 & 70,83 & 77,34 & 80,58 & 83,21 \\
Nutrientes digestíveis totais & 56,08 & 63,54 & 69,25 & 75,42 & 81,40
\end{tabular}

Fonte: Cabral et al. (2002).

na redução da digestibilidade total $(64,80 \times 59,96 \%)$ e ruminal da FDN $(77,77 \times 71,20 \%)$, bem como do tempo de retenção ruminal $(20,40 \times 16,68$ h). Contudo, Franco et al. (2002) não constataram diferenças no $\mathrm{pH}$ ruminal $(6,79$ vs. 6,65$)$ e na degradabilidade da FDN $(54,46$ vs. $54,34 \%$ ) de bovinos pastejando Brachiaria brizantha 'Marandu' $10,3 \%$ de PB; $69,5 \%$ de FDN e 34,5\% de FDA), suplementados com 1,0 kg/animal/dia de grãos de milho.

A variação da fonte e da degradabilidade dos $\mathrm{CNF}$ da fonte de amido pode maximizar a síntese de proteína microbiana no rúmen e a eficiência de utilização da proteína não degradável no rúmen. Para bovinos machos castrados alimentados com silagem de milho, Fregadolli et al. (2001) estimaram maior digestão ruminal da FDN com a suplementação de amido na forma de grãos de milho $(39,3 \%)$, comparativamente à casca de mandioca $(25,9 \%)$, evidenciando o efeito da degradabilidade da fonte de CNF sobre a digestão da FDN. $\mathrm{O}$ valor mínimo médio do $\mathrm{pH}$ do líquido ruminal para as rações com milho foi e 6,2 e para as com casca de mandioca foi de 6,1. Para novilhos de corte pastejando Panicum maximum 'Mombaça' e suplementados com 8,0 $\mathrm{kg} /$ dia de suplemento energético contendo $86,6 \%$ de raspa de mandioca $(3,0 \%$ de $\mathrm{PB} ; 8,6 \%$ de $\mathrm{FDN} ; 5,3 \%$ de FDA e 78,0\% de CNF), Rocha (2010) constataram acréscimos na digestibilidade da MS $(47,46 \times 43,33 \%)$, da PB $(60,68 \times 61,94 \%)$, da FDN $(50,36 \times 46,16 \%)$ e dos CNF $(49,09 \times 55,97 \%)$.

\section{SUPLEMENTOS PROTÉICOS}

Os ruminantes necessitam de dois tipos de proteína: a proteína degradável no rúmen (PDR), necessária para atender às exigências dos microrganismos ruminais e a proteína não degradada no rúmen (PNDR), para atender às exigências dos animais. A PNDR é formada pela proteína bypass presente nos alimentos, que podem ser supridas pelas forrageiras ou suplementos. A exigência de PDR é de aproximadamente $130 \mathrm{~g} / \mathrm{kg}$ de matéria orgânica digestível (Klopfenstein, 1996). A principal fonte de proteína para animais mantidos em pastagens é a proteína microbiana e para a sua síntese é necessária a presença de esqueletos de carbono, $\mathrm{N}$ e condições favoráveis para o crescimento microbiano (temperatura e $\mathrm{pH})$. O esqueleto de carbono é fornecido através da fermentação dos carboidratos das forrageiras, enquanto que o N é oriundo da degradação da proteína presente na planta e da reciclagem de saliva, característica dos animais ruminantes. A saliva é responsável pelo fornecimento de $\mathrm{N}$ para os microrganismos em situações de deficiência protéica. O nível mínimo de proteína na dieta varia entre $6-8 \%$ de $\mathrm{PB}$. Se a dieta não fornecer esta quantidade, a reciclagem não será suficiente para atender às necessidades da flora ruminal, o que causará diminuição do consumo e da digestibilidade das forrageiras (Van Soest, 1994).

$\mathrm{O}$ fornecimento adicional de $\mathrm{N}$ para animais consumindo forragens tropicais de baixa qualidade favorece o crescimento das bactérias fibrolíticas, aumenta a taxa de digestão e a síntese de proteína microbiana e, consequentemente aumenta o consumo voluntário e melhora o balanço energético a partir dos CF da forragem. Deste modo, incrementa-se o aproveitamento dos substratos energéticos do próprio suplemento, resultando em maior aporte de nutrientes para o intestino e ácidos graxos voláteis para o metabolismo energético (Detmann et al., 2004, 2008). A elevada proporção de compostos nitrogenados insolúveis em detergente neutro verificada em gramíneas tropicais é considerada de lenta e incompleta degradação, pode implicar na carência de compostos nitrogenados aos microrganismos ruminais para máxima produção de proteína microbiana (Paulino et al., 2006; Muniz et al., 2012). O fornecimento de uma fonte de PDR ou uma fonte de compostos não-protéicos (NNP) que atenda às necessidades das bactérias fibrolíticas nas situações onde há limitação de $\mathrm{N}$, sua população aumenta significativamente, pois requerem como principal fonte de $\mathrm{N}$ o íon amônio $\left({\mathrm{N}-\mathrm{H}_{4}+}^{+}\right)$, liberados a partir da degradação ruminal da PDR e do NNP (Russell et al., 1992).

Para vacas leiteiras sob pastejo em capim-elefante (Pennisetum purpureum), o fornecimento de suplementos nitrogenados resultou em acréscimos significativos na digestibilidade da FDN (49,9 e 54,3\%, respectivamente para 11 e $13 \%$ de PB) (Silva et al., 2009). A inclusão de $2 \%$ de uréia ao feno de $C$. dactylon 'Coast Cross' afetou positivamente a taxa de degradação $\left(0,06 \times 0,11 \mathrm{~h}^{-1}\right)$ e a degradabilidade efetiva da FDN $(30,12 \times 41,07 \%)$ (Lopes et al., 2010). Silveira (2002), avaliando o feno da mesma gramínea, verificou uma resposta linear significativa para a digestibilidade da FDN, em função dos níveis de PB da dieta $(62,95 ; 67,14$; 68,91 e $69,25 \%$, respectivamente para 9,$52 ; 13,26 ; 15,08$ e $18,41 \%$ de PB). Em pastagens de Panicum maximum 'Tanzânia' (6,4\% de PB e 72,1\% de FDN), a suplementação protéica proporcionou incrementos lineares na digestibilidade da FDN (23,8; 46,0 e 53,8\%, respectivamente para 0,$0 ; 40,8$ e $70,2 \%$ de farelo de soja), não sendo constatado efeito substitutivo no consumo da forragem da gramínea (Baroni et al., 2010a,b). Para bovinos alimentados com feno de Brachiaria decumbens de baixa qualidade $(5,08 \%$ de $\mathrm{PB}$ e $83,55 \%$ de FDN), a suplementação com compostos nitrogenados permitiu a elevação do teor de $\mathrm{PB}$ da dieta em níveis próximos a $11 \%$ proporcionando a otimização da utilização da forragem. A taxa de passagem de partículas fibrosas e, consequentemente, o efeito de repleção ruminal da FDN indigestível foram os fatores mais limitantes ao consumo e a degradação dos componentes fibrosos. 
Tabela III. Digestibilidade da matéria seca (DMS), proteína bruta (DPB), fibra em detergente neutro corrigida para cinzas e proteína (FDNcp) e potencialmente degradável (FDNpd), $\mathrm{pH}$ ruminal, tempo de retenção ruminal (TRR), taxa de degradação da FDN (TDFDN) e fração efetivamente degradada da FDN (FEDFDN) do feno de Brachiaria decumbens, em função dos níveis de proteína na dieta (Dry matter digestibility (DMS), crude protein (DPB), neutral detergent fiber corrected for ash and protein (FDNcp) and potentially degradable (FDNpd), ruminal $\mathrm{pH}$, ruminal retention time (TRR), FDN degradation rate (TDFDN) and effectively degraded fraction of FDN (FEDFDN) of Brachiaria decumbens hay, as affected by levels of protein in the diet).

\begin{tabular}{lccccc}
\hline Variável & \multicolumn{5}{c}{ Níveis de proteína bruta na dieta (\%) } \\
\cline { 2 - 6 } & 5,28 & 8,08 & 9,82 & 11,87 & 13,63 \\
\hline DMS (\%) & 41,41 & 46,61 & 44,95 & 47,05 & 48,04 \\
DPB (\%) & 32,22 & 55,63 & 62,20 & 69,72 & 74,10 \\
FDNcp (\%) & 46,94 & 53,62 & 51,25 & 52,54 & 53,26 \\
FDNpd (\%) & 75,04 & 83,39 & 84,27 & 85,29 & 86,44 \\
pH ruminal & 6,78 & 6,31 & 6,60 & 6,61 & 6,42 \\
TRR (h) & 193,41 & 133,49 & 153,03 & 138,86 & 140,20 \\
TDFDN (h-1) & 0,1761 & 0,1826 & 0,1804 & 0,2158 & 0,1863 \\
FEDFDN (\%) & 32,97 & 44,92 & 46,08 & 43,38 & 47,03 \\
\hline
\end{tabular}

Fonte: Lazzarini (2007).

Teores de PB próximos a $8 \%$ foram necessários para que os microrganismos ruminais apresentassem capacidade plena de utilização dos CF da forragem basal de baixa qualidade (Lazzarini, 2007) (tabela III).

A atividade dos microrganismos celulolíticos é muito dependente da concentração de amônia no rúmen, sendo a concentração mínima estimada em 5 mg N-NH$H_{3} / d L$ de líquido ruminal para que não ocorra limitação na fermentação microbiana. Contudo, para gramíneas tropicais são necessários 10 a 20 mg $\mathrm{N}-\mathrm{NH}_{3} / \mathrm{dL}$ para que se maximize a degradação ruminal e o consumo de MS, respectivamente (Leng, 1990). Estas variações refletem as exigências microbianas em função do substrato basal, do pH ruminal e das interações que ocorrem entre espécies microbianas e o substrato degradado (Hoover, 1993). Para bovinos recebendo dieta à base de $B$. decumbens, a concentração de amônia no rúmen foi proporcional aos níveis de PB proporcionados pelo suplemento nitrogenado $(3,82$; 6,$32 ; 9,62,8,72$ e $14,24 \mathrm{mg} \mathrm{N}-\mathrm{NH}_{3} / \mathrm{dL}$, respectivamente para 5,$19 ; 7,11 ; 8,60 ; 11,67$ e $13,02 \%$ de PB), a qual implicou em menor tempo de retenção ruminal do alimento e maiores taxas de degradação da FDN (Sampaio et al., 2009).

\section{SUPLEMENTOS ENERGÉTICOS E PROTÉICOS}

Os microrganismos ruminais dependem de fontes de energia e $\mathrm{N}$ fermentáveis para suas atividades metabólicas, influenciando fortemente a digestibilidade ruminal e, consequentemente, o fluxo de nutrientes, tanto de ácidos graxos voláteis quanto de proteína microbiana para o ruminante. $\mathrm{O}$ nutriente exigido em maior quantidade pelos ruminantes, após a energia, é a proteína, que tem como principal função fornecer os aminoácidos para a promoção dos muitos processos de síntese que ocorrem no organismo dos ruminantes (Dutra et al., 1997). A sincronia entre a fermentação energética e a degradação da PB é essencial para eficiente utilização da energia e da proteína pelos microrganismos ruminais (Ekinci e Broderick, 1997). Considerando que os carboidratos são a principal fonte de energia para o crescimento microbiano e a proteína microbiana, a principal fonte de aminoácidos para o hospedeiro, as variações em suas frações, bem como nas taxas de digestão entre e dentro de alimentos, podem afetar o suprimento de proteína microbiana ao intestino delgado e, conseqüentemente, o desempenho animal.

A capacidade de utilização do NNP pelas bactérias depende, primariamente, da quantidade e do nível de degradação da energia fornecida ao animal (carboidratos) e da capacidade de crescimento da população de microrganismos, o qual é limitado pela ingestão de energia. As bactérias celulolíticas usam basicamente $\mathrm{N}$ amoniacal $\left(\mathrm{N}-\mathrm{NH}_{3}\right)$ como fonte de $\mathrm{N}$, uma vez que sua capacidade de usar $\mathrm{N}$ na forma de aminoácidos e peptídeos é bastante reduzida. As bactérias amilolíticas crescem mais rapidamente utilizando cerca de $60 \%$ de peptídeos e aminoácidos e $34 \%$ de $\mathrm{N}$ amoniacal como fontes de N para seu crescimento (Russell, 1998). Além disso, as bactérias que degradam o amido, pectina ou açúcares são capazes de continuar a degradação do substrato mesmo quando o $\mathrm{N}$ é limitante no meio (Russell, 2002). Dessa forma, maiores concentrações de $\mathrm{N}-\mathrm{NH}_{3}$ são dependentes da degradabilidade da fonte protéica, da disponibilidade de carboidratos e do equilíbrio entre sua produção e utilização pelos microrganismos (Satter e Roffler, 1979; Nocek e Russell, 1998).

A energia e o $\mathrm{N}$ são os principais fatores que afetam a eficiência da síntese de proteína microbiana. A suplementação com fontes de proteína verdadeira permite corrigir a deficiência de energia, pois promove aumento na proporção de microrganismos no rúmen e, conseqüentemente, eleva a digestibilidade da forragem de baixa qualidade e os consumos de MS e energia digestível, ocasionando melhor desempenho dos animais (Reis et al., 1997). A suplementação com proteína de baixa degradabilidade ruminal, permite que os aminoácidos sejam absorvidos no intestino delgado, promovendo um efeito positivo sobre o consumo de forragem e o desempenho animal (Siebert e Hunter, 1982; Russell e Wilson, 1996).

A utilização de dietas ricas em carboidratos, principalmente de fontes de alta degradabilidade associadas à fontes protéicas de baixa degradabilidade, pode originar situações com excesso de energia e deficiência de $\mathrm{N}$ para a fermentação ruminal. O excesso de energia acaba sendo utilizado apenas para a manutenção microbiana, sem gerar efeitos nos processos de síntese e crescimento da microbiota e até mesmo acarretando a utilização de ciclos fúteis para eliminação do excesso de carboidratos ou ainda ser depositado na forma de gordura (Russel, 1998). Por outro lado, não havendo disponibilidade adequada de carboidratos no momento da liberação da amônia no rúmen, ela não será incorporada à massa microbiana, sendo então, absorvida do rúmen para corrente sanguínea e, posteriormente, eliminada pela urina como uréia. Este processo meta- 
Tabela IV. Digestibilidade da matéria seca (DMS), da fibra em detergente neutro (DFDN), FDN potencialmente digestível (FDNpd), pH ruminal, nitrogênio amoniacal ruminal (NAR), taxa de degradaçăo da FDN (TDFDN) e tempo de retenção ruminal (TRR) do feno de Brachiaria decumbens, em função da suplementação com proteína e/ou carboidratos $(\mathrm{CHO})$ (Dry matter digestibility (DMS), digestibility of neutral detergent fiber (DFDN), potentially digestible of FDN (FDNpd), ruminal $\mathrm{pH}$, ruminal ammonia nitrogen (NAR), FDN degradation rate (TDFDN) and rumen retention time (TRR) of Brachiaria decumbens hay, according to the supplementation with protein and/or carbohydrate $(\mathrm{CHO})$.

\begin{tabular}{lcccccc}
\hline Variáveis & \multicolumn{2}{c}{ Sem proteína } & & \multicolumn{2}{c}{ Com proteína } \\
\cline { 2 - 3 } \cline { 6 - 7 } & Sem CHO & Com CHO & & Sem CHO & Com CHO \\
\hline DMS (\%) & 32,0 & 43,0 & & 44,1 & 48,3 \\
DFDN (\%) & 39,7 & 38,8 & & 48,2 & 43,8 \\
FDNpd (\%) & 64,0 & 61,3 & & 76,8 & 70,1 \\
pH & 6,76 & 6,72 & & 6,48 & 6,20 \\
NAR (mg/dL) & 2,74 & 2,53 & & 9,72 & 6,24 \\
TDFDN (h-1) & 0,2507 & 0,1795 & & 0,2043 & 0,1595 \\
TRR (h) & 138,9 & 117,6 & & 121,1 & 91,7 \\
\hline
\end{tabular}

Fonte: Souza (2007).

bólico é indesejável, pois requer o uso de energia que, poderia ser utilizada para a produção. Se a liberação de amônia no rúmen ultrapassar a capacidade de metabolização do animal (acima de $75 \mathrm{mg} / 100 \mathrm{ml}$ de líquido ruminal) pode ocorrer intoxicação, podendo inclusive levar o animal à morte. Portanto, a participação do NNP na dieta é dependente do nível energético da mesma (Thiago, 1999).

Para otimização da produção de proteína microbiana é necessário que haja sincronia entre a disponibilidade de energia e compostos nitrogenados no ambiente ruminal (Russel et al., 1992). Os microorganismos são dependentes de ATP, energia proveniente da fermentação dos carboidratos para que ocorra a biossíntese da proteína microbiana. Quando há déficits de energia, os peptídeos e aminoácidos são utilizados como fonte de energia, ocorrendo o acúmulo de $\mathrm{N}_{-} \mathrm{NH}_{3}$ no meio. Dessa forma, esta variável é dependente da degradabilidade da fonte protéica, da disponibilidade de carboidratos e do equilíbrio entre sua produção e utilização pelos microorganismos (Nocek e Russel, 1988). Deste modo, a degradação dos nutrientes é determinada pela competição entre taxa de degradação e passagem, e o conhecimento de ambas é necessário para estimar as quantidades de energia e de compostos nitrogenados disponíveis no rúmen (Russel, 1998). Souza (2007), em bovinos alimentados com feno de $B$. decumbens de baixa qualidade $(86,4 \%$ de FDN e $5,16 \%$ de $\mathrm{PB}$ ), constatou aditividade entre os efeitos da suplementação protéica e com carboidratos, contudo os efeitos benéficos da suplementação protéica não foram suficientes para anular os efeitos deletérios dos carboidratos sobre a dinâmica ruminal da degradação da FDN (tabela IV). Benez (2007) verificou que o aumento dos níveis de concentrado protéico-energético na dieta de bovinos recebendo feno de $B$. decumbens implicou em diminuição do $\mathrm{pH}$ ruminal e maiores concentrações de $\mathrm{N}-\mathrm{N}_{3}$, o que contribui para uma maior degradabilidade da FDN. No entanto, Ladeira et al. (1999), utilizando suplementos energéticos-proteicos (milho + farelo de soja), constataram que a digestibilidade da FDN foi afetada pelo nível de concentrado fornecido aos animais, sendo o maior valor registrado com a inclusão de $25 \%$ do concentrado à ração $(64,7 \%)$, ocorrendo decréscimos à medida que se aumentaram seus níveis à dieta $(55,0 ; 56,2 ; 56,8$ e $58,8 \%$, respectivamente para 37,$5 ; 60,0 ; 62,5$ e $75 \%$ de concentrados).

A cinética de degradação de carboidratos e proteínas varia amplamente de acordo com alimento, sua composição e arranjo estrutural, além do método de processamento. A extensão da degradação protéica no rúmen é determinada pela atividade proteolítica microbiana, taxa de reciclagem no rúmen e oportunidade de acesso do microorganismo ao nutriente, determinada pela permanência do alimento no rúmen (Paulino et al., 2006). A sincronização entre as fontes de carboidratos (que forneceriam energia e esqueletos carbônicos para os microrganismos) e as de $\mathrm{N}$ pode acarretar maximização da eficiência microbiana e diminuição da perda de $\mathrm{N}$ em forma de amônia e da energia dos carboidratos, promovendo melhoria na digestão da MS e, especialmente, da fração fibrosa. A maior eficiência microbiana pode promover o aumento na disponibilidade de proteína microbiana para ser absorvida no intestino, suprindo, assim, as exigências de animais em crescimento (Caldas Neto et al., 2008; Muniz et al., 2012). Fregadolli et al. (2001) constataram que as fontes de amido, de alta (casca de mandioca) e baixa degradabilidade ruminal (milho), em combinação com fontes de nitrogênio, de alta (levedura) e baixa degradabilidade ruminal (farinha de ossos e carne + farelo e algodão), interagiram-se somente para a digestibilidade no trato gastrintestinal da PB e da FDN. Os demais parâmetros analisados foram influenciados pela fonte de amido ou pela fonte de N. A fonte de amido teve efeito sobre a digestibilidade aparente ruminal do amido e a fonte de $\mathrm{N}$ sobre a digestibilidade total e ruminal do amido e da energia bruta. Os altos valores negativos para a digestão ruminal da PB refletiram em inadequado suprimento de $\mathrm{N}$ e de sua reciclagem, sendo mais evidente para a ração com casca de mandioca e levedura do que para as rações com milho e farelo de algodão + farinha de carne e ossos, milho e levedura e casca de mandioca e farelo de algodão + farinha de carne e ossos (tabela V). Costa et al. $(2008,2009)$ observaram que a suplementação de forragem de baixa qualidade com compostos nitrogenados apresentou natureza prioritária, pois incrementou a utilização dos CF pelos microrganismos ruminais. A suplementação com carboidratos apresentou aspectos secundários sobre a utilização da fibra da forragem, sendo verificados efeitos inibitórios in vitro sobre a utilização da fibra basal, quando as fontes de carboidratos foram baseadas em amido, ou efeitos pouco representativos, quando utilizada a pectina (tabela VI).

\section{CONSUMO VOLUNTÁRIO E DEGRADACCÃO DA FIBRA}

O desempenho animal é dependente da ingestão de nutrientes digestíveis e metabolizáveis, sendo 60 a $90 \%$ explicados pelas variações no consumo de MS e apenas 10 a $40 \%$ pela digestibilidade da dieta. A principal variável que afeta o desempenho animal é 
Tabela V. Digestibilidade da matéria seca (DMS), da proteína bruta (DPB), da fibra em detergente neutro (DFDN), do amido (DA) e digestão ruminal (DR), em função da suplementação com amido e proteína de baixas e altas degradabilidades (Dry matter digestibility (DMS), crude protein digestibility (DPB), neutral detergent fiber digestibility (DFDN), starch digestibility (DA) and ruminal digestion (DR), as affected by starch supplementation and protein low and high degradability).

\begin{tabular}{lcccc}
\hline Variáveis & \multicolumn{2}{c}{ AM } & \multicolumn{2}{c}{ ACM } \\
\cline { 2 - 5 } & PBD & PAD & PBD & PAD \\
\hline DMS (\%) & 52,7 & 53,2 & 49,4 & 61,4 \\
DPB (\%) & 51,1 & 57,2 & 56,1 & 52,2 \\
DFDN (\%) & 43,7 & 34,8 & 25,4 & 26,6 \\
DA (\%) & 76,1 & 69,1 & 95,1 & 88,2 \\
DR (\%) & 47,8 & 58,4 & 53,1 & 68,1 \\
\hline
\end{tabular}

$\mathrm{AM}=$ Amido de baixa degradabilidade Milho; $\mathrm{ACM}=$ Amido de alta degradabilidade casca de mandioca; $P B D=$ Proteína de baixa degradabilidade (farinha de carne e ossos + farelo de algodão). PAD= Proteína de alta degradabilidade (levedura). Fonte: Fregadolli et al. (2001).

o consumo, o qual está diretamente relacionado com a eficiência do ruminante em processar e utilizar o alimento para a produção de energia. O consumo de MS, geralmente, é determinado como a capacidade do rúmen de acomodar e passar ao intestino os resíduos que não são digeridos e, as taxas de digestão da fibra no rúmen determinam as alterações neste processo, afetando o nível de ingestão e a quantidade de nutrientes disponíveis para a manutenção e produção do animal (Dixon e Stockdale, 1999). O consumo voluntário depende das taxas de digestão e de passagem, sendo a digestibilidade altamente correlacionada com o espaço de tempo que uma partícula do alimento permanece no interior do trato digestivo (Campling e Freer, 1966; Thornton e Minson, 1972; Poppi e McLennan, 1995). As diferenças na velocidade de degradação interferem na eficiência e no equilíbrio do fluxo de substrato disponível para os microrganismos do rúmen (McCarthy Junior et al., 1989). O desaparecimento da FDN no ambiente ruminal constitui a integração entre o processo de degradação de sua fração potencialmente degradável e o da retirada da fração indigestível, processos determinantes sobre o consumo voluntário sob dietas com predomínio de forragens tropicais (De- tmann et al., 2003). O consumo voluntário de forragens de baixa digestibilidade é limitado pela distensão física do trato gastrintestinal, a qual diminui à medida que a digestibilidade aumenta. Possivelmente, interações entre a dieta e o animal afetem o mecanismo específico pelo qual o fluxo através do orifício retículo omasal é regulado. Quando a ingestão de MS é limitada pela distensão no rúmen-retículo a limitação resulta da quantidade da digesta dentro e do fluxo da digesta saindo do rúmen-retículo. A redução no tamanho de partícula é requisito para saída do rúmen-retículo, entretanto a passagem das partículas pelo orifício retículo-omasal depende, principalmente, da sua densidade. À medida que o alimento é fermentado, a FDN potencialmente digestível é removida aumentando a quantidade relativa de FDN indigestível. O gás produzido pela fermentação diminui à medida que a fração potencialmente fermentável diminui, logo, a probabilidade de passagem para o omaso aumenta à medida que a densidade da partícula aumenta (Leng, 1990; Allen, 1996).

As relações com baixa ou alta proporção de concentrado:volumoso implicam redução da síntese de proteína microbiana, decréscimo na degradabilidade do substrato e alteração na velocidade de passagem do alimento no trato gastrintestinal do ruminante e, consequentemente no consumo de MS. Para cada $1 \mathrm{~g}$ de matéria orgânica fermentável no rúmen aproximadamente $0,22 \mathrm{~g}$ é utilizado para a síntese de proteína microbiana, a qual tem a função de suprir a necessidade protéica do animal, sendo recomendadas faixas de 30 a $40 \%$ de concentrados e 60 a $70 \%$ de volumosos (Hagemeister et al., 1981). A reduzida relação volumoso:concentrado pode ter consequência imediata sobre o rendimento produtivo do sistema, uma vez que compromete a utilização dos componentes fibrosos da forragem como precursores para a síntese de produto animal (Detmann et al., 2004). Dietas ricas em volumosos, normalmente, favorecem o aumento do pH ruminal e resultam em aumentos da população de bactérias celulolíticas, contudo quando suas partículas são muito pequenas tende a ocorrer redução do $\mathrm{pH}$ ruminal devido a maior taxa de fermentação no rúmen (Cheng e Hironaka, 1973; Church, 1990).

Alimentos volumosos de baixa digestibilidade podem reduzir o consumo de MS, pois em razão de sua baixa degradação, seu lento desaparecimento e menor

Tabela VI. Máxima taxa de degradação da fibra em detergente neutro (TDFDN), fração efetivamente degradada da FDN (FEDFDN), taxa específica de crescimento microbiano (TECM), eficiểncia de crescimento microbiano sobre a FDN (ECM) e pH ruminal, em função da suplementação protéica e/ou com carboidratos (Maximum fiber degradation rate of neutral detergent fiber (TDFDN), effectively degraded fraction of FDN (FEDFDN), specific rate of microbial growth (TECM), microbial growth efficiency on FED (ECM) and ruminal pH, as affected by protein supplement and/or carbohydrates).

\begin{tabular}{lccccc}
\hline Tratamentos & TDFDN $\left(\mathrm{h}^{-1}\right)$ & FEDFDN $(\%)$ & TECM $\left(\mathrm{h}^{-1}\right)$ & $\mathrm{ECM} \mathrm{g} \mathrm{MS} / \mathrm{kg}^{* *}$ & $\mathrm{pH}$ \\
\hline Feno* & 0,9578 & 51,70 & 0,0192 & 195,9 & 7,00 \\
Feno + amido & 0,7971 & 46,46 & 0,0160 & 177,8 & 6,95 \\
Feno + pectina & 1,1135 & 55,23 & 0,0224 & 211,3 & 6,95 \\
Feno + proteína & 1,2497 & 59,79 & 0,0250 & 222,2 & 6,95 \\
Feno + proteína + amido & 1,0151 & 53,99 & 0,0204 & 202,0 & 6,95 \\
Feno + pectina + proteína & 1,2442 & 59,67 & 0,0250 & 222,2 & 7,00
\end{tabular}

*Feno de Brachiaria decumbens (3,8\% de PB e $84,5 \%$ de FDN); ${ }^{* *} \mathrm{ECM}=\mathrm{g}$ de matéria seca microbiana/kg de carboidrato degradado no rúmen. Fonte: Costa et al. $(2008,2009)$. 
Tabela VII. Ingestão de matéria seca (MS) do volumoso e total, da fibra em detergente neutro (FDN) e de carboidratos não fibrosos (CNF) do feno de Brachiaria decumbens, em função dos níveis de suplemento protéicoenergético (Intake of dry matter (MS) of forage and total, intake of neutral detergent fiber (FDN) and non-fiber carbohydrates (CNF) of Brachiaria decumbens hay, as affected by protein-energy supplementation levels).

Ingestão de matéria seca

Ingestão de suplemento protéico-energético (\% peso vivo/dia)

(em peso vivo)

\begin{tabular}{lrrrrr}
\hline & \multicolumn{1}{c}{0} & 0,25 & 0,5 & 1,0 & 1,25 \\
\hline MS volumoso (\%) & 1,68 & 1,79 & 1,71 & 1,46 & 1,43 \\
MS total (\%) & 1,68 & 2,03 & 2,20 & 2,42 & 2,87 \\
FDN volumoso (g/kg) & 10,85 & 11,53 & 11,15 & 9,21 & 8,67 \\
FDN concentrado (g/kg) & 0,00 & 0,25 & 0,51 & 1,00 & 1,50 \\
FDN total (g/kg) & 10,85 & 11,78 & 11,66 & 10,21 & 10,17 \\
CNF (g/kg) & 2,49 & 2,43 & 2,46 & 2,47 & 2,49 \\
\hline
\end{tabular}

Fonte: Benez (2007).

taxa de passagem para o trato gastrintestinal, podem causar efeito de enchimento ruminal. Tal efeito é devido a fatores fisiológicos como os receptores de tensão localizados na parede do rúmen que, quando estimulados inibem o consumo voluntário, atuando como um mecanismo de controle metabólico. Para animais alimentados com dietas de alta digestibilidade, igual ou superior a $65 \%$, a ingestão voluntária é controlada principalmente pelas alterações nos processos bioquímicos de digestão (Forbes, 1995; Allen, 1996). Elevados teores de CNF na dieta comprometem a utilização da fibra pelos microrganismos ruminais, afetando negativamente a renovação das partículas residentes no rúmen (Mould et al., 1983).

O teor de FDN pode ter grande influência no consumo de MS, devido a sua menor taxa de passagem em relação aos outros nutrientes da dieta, tendo como conseqüência maior permanência da digesta no trato gastrintestinal. Deste modo, quando houver uma maior indegistibilidade da forragem, o enchimento tornar-se-á um fator limitante da ingestão (Forbes e France, 1993; Mertens, 1994; Allen, 2000; Silva et al., 2009). O consumo voluntário de forragem pode ser maximizado quando a ingestão de FDN diária for de aproximadamente $12,5 \mathrm{~g} / \mathrm{kg}$ de peso vivo (Bonhnert et al., 2002). Oba e Allen (1999) constataram que o aumento de uma unidade percentual na digestibilidade in vitro ou in situ da FDN foi associado ao incremento de $0,17 \mathrm{~kg} /$ dia no consumo de MS e de 0,25 kg/dia na produção de leite. Benez (2007) reportou incrementos no consumo voluntário de MS por bovinos alimentados com feno de $B$. decumbens, à medida que os teores de FDN da dieta foram reduzidos pela adição de milho em grãos e farelo de soja. Silva et al. (2007), para bovinos alimentados com feno de Tifton 85 (84,56\% de FDN), verificaram que a inclusão de $4,3 \%$ de amido na dieta implicou na redução do consumo de FDN (3,94×3,72 kg/dia), contudo o consumo de MS não foi afetado $(4,70 \times 4,69 \mathrm{~kg} /$ dia $)$. Em pastagens de Cynodon dactylon, Berchielli et al. (2001) observaram uma relação negativa entre teor de FDN da forragem e o consumo voluntário de vacas em lactação, o qual foi reduzido de 1,17 para $0,95 \%$ do peso vivo quando o teor de FDN aumentou de 69,1 para $70,5 \%$. Para cabras leiteiras alimentadas com feno de Cynodon spp. 'Tifton, Branco' et al. (2010) constataram que o consumo de FDN foi diretamente proporcional ao seu incremento na dieta $(0,61 ; 0,71 ; 0,69 ; 0,78$ e $0,76 \mathrm{~kg} /$ dia, respectivamente para $19 ; 27 ; 35 ; 42$ e $48 \%$ de FDN), ocorrendo o inverso quanto ao consumo de MS, o qual foi reduzido de 2,17 para $1,52 \mathrm{~kg} /$ dia quando o teor de FDN passou de 19 para $43 \%$.

A inclusão de maiores quantidades de concentrados na dieta de bovinos proporciona menor ingestão de FDN e, consequentemente, fornece menor quantidade de substrato para as bactérias celulolíticas, em decorrência da grande proporção de carboidratos rapidamente fermentáveis que direciona a fermentação ruminal para a produção de ácido propiônico, causando uma redução no $\mathrm{pH}$ ruminal e tornando o ambiente desfavorável para as bactérias celulolíticas (Berchie1 li et al., 2001). Quando o suplemento fizer parte de mais de $25 \%$ da dieta total pode ocorrer redução do consumo total de forragem, implicando num efeito substitutivo (Obara et al., 1991). Contudo, nem sempre o decréscimo no consumo e na digestibilidade da fibra associados com a suplementação de energia é causado pela diminuição do pH (Caton e Dhuyvetter, 1997). Os suplementos energéticos são utilizados com o objetivo de suprir as exigências em energia, consideradas em pastejo como as mais limitantes ao desempenho animal. Os efeitos associativos negativos como depressão ou substituição, dependem do nível de suplementação e podem resultar em diminuições na digestibilidade da FDN e no consumo do volumoso (Ørskov, 1999; Romney e Gill, 2000).

$\mathrm{O}$ aumento na taxa de passagem normalmente reduz a disgestibilidade dos componentes mais resistentes à degradação, como fibra e amido de baixa degradabilidade ruminal (Russel e Wilson, 1996). Baixa concentração ruminal de amônia e de AGV de cadeia ramificada, assim como deficiências minerais, também podem desencadear reduções na digestibilidade da dieta e no consumo de forragem. Para bovinos alimentados com feno de B. decumbens, Benez (2007) constatou aumentos nos níveis de ingestão de MS do volumoso e total, FDN do concentrado e de CNF, à medida que se aumentaram os níveis de ingestão do suplemento protéico-energético $(80 \%$ de grãos de milho; $13,4 \%$ de farelo de soja; $2,8 \%$ de uréia e 3,8\% de Fosbovi $20^{\circledR}$ ), ocorrendo o inverso quanto ao consumo 
Tabela VIII. Consumo de matéria seca total (MST) e da forragem (MSF), da fibra detergente neutro (FDN) e de carboidratos não fibrosos (CNF) por vacas alimentadas com feno de Brachiaria decumbens, em função da suplementação com proteína e/ou carboidratos (CHO) (Total dry matter intake (MST) and forage intake (MSF), neutral detergent fiber intake (FDN) and non-fiber carbohydrates intake (CNF) for cows fed Brachiaria decumbens hay, as affected by supplementation with protein and/or carbohydrates $(\mathrm{CHO})$.

\begin{tabular}{lcccc}
\hline \multirow{2}{*}{ Variáveis } & \multicolumn{2}{c}{ Sem proteína } & \multicolumn{2}{c}{ Com proteína } \\
\cline { 2 - 5 } & \multicolumn{2}{c}{ Sem CHO } & Com CHO & Sem CHO Com CHO \\
\hline MST (kg/dia) & 3,457 & 3,494 & 4,479 & 4,938 \\
MST (g/kg peso vivo) & 15,2 & 15,2 & 19,0 & 22,0 \\
MSF (kg/dia) & 3,457 & 2,968 & 4,235 & 4,036 \\
FDN (kg/dia) & 2,987 & 2,566 & 3,653 & 3,483 \\
FDN (g/kg peso vivo) & 13,2 & 11,1 & 15,5 & 15,0 \\
CNF (kg/dia) & 0,193 & 0,691 & 0,222 & 0,886 \\
\hline
\end{tabular}

Fonte: Souza (2007).

Tabela IX. Consumo de matéria seca (CMS) e digestibilidade aparente da MS (DMS), da proteína bruta (DPB) e da fibra em detergente neutro (DFDN), em bovinos de corte suplementados com farelo de soja, ureia ou amireia (Dry matter intake (CMS) and apparent digestibility (DMS), crude protein digestibility (DPB) and neutral detergent fiber digestibility (DFDN) in beef cattle supplemented with soybean meal, urea or starea).

\begin{tabular}{lccc}
\hline Variáveis & Farelo de soja & Ureia & Amireia \\
\hline CMS (kg/dia) & $5,85^{\mathrm{b}}$ & $7,55^{\mathrm{a}}$ & $7,55^{\mathrm{a}}$ \\
DMS (\%) & $67,10^{\mathrm{a}}$ & $76,10^{\mathrm{a}}$ & $76,30^{\mathrm{a}}$ \\
DPB (\%) & $76,8^{\mathrm{a}}$ & $84,1^{\mathrm{a}}$ & $83,7^{\mathrm{a}}$ \\
DFDN (\%) & $51,6^{\mathrm{b}}$ & $67,2^{\mathrm{a}}$ & $66,5^{\mathrm{a}}$ \\
\hline
\end{tabular}

Médias seguidas de mesma letra não diferem entre si pelo teste de Tukey $(p>0,05)$. Fonte: Oliveira Júnior et al. (2004).

de FDN do volumoso (tabela VII). Para vacas alimentadas com feno de C. dactylon (74,5\% de FDN e 12,4\% de PB), Goetsch et al. (1991) reportaram que para cada $\mathrm{kg} /$ dia de milho consumido houve uma diminuição de $3,3 \%$ na digestibilidade da FDN, o que significou uma redução de $8,3 \%$ para cada $1 \%$ do peso vivo de suplementação com milho. Souza (2007), em bovinos alimentados com feno de $B$. decumbens de baixa qualidade $(86,4 \%$ de $\mathrm{FDN}$ e $5,16 \%$ de $\mathrm{PB})$, verificou efeitos positivos e negativos, respectivamente para a suplementação com proteína e carboidratos, as quais refletiram alterações sobre a digestibilidade da FDN, além de um efeito interativo sobre o metabolismo dos compostos nitrogenados, sendo a assimilação de $\mathrm{N}$ no ambiente ruminal otimizada quando do fornecimento conjunto dos suplementos (tabela VIII). Da mesma forma, Oliveira Júnior et al. (2004), para bovinos de corte alimentados com bagaço de cana, não observaram diferenças para a digestibilidade da MS e da $\mathrm{PB}$, contudo o consumo de MS e a digestibildade da FDN foram significativamente incrementadas com a adição de uréia ou amireia à dieta, comparativamente a inclusão do farelo de soja (tabela IX). Em pastagens de Panicum maximum 'Tanzânia', Baroni et al. $(2010 \mathrm{a}, \mathrm{b})$ verificaram que a suplementação protéica $(0,0 ; 40,8$ e $70,2 \%$ de farelo de soja) proporcionou incrementos lineares no consumo total de MS e de FDN, os quais foram potencializados com a adição de $28,6 \%$ de farelo e milho. O consumo de FDN ficou abaixo do esperado, média de $5,7 \mathrm{~g} / \mathrm{kg}$ de peso vivo, se comparado ao valor de 12,0 g/ kg de peso vivo sugerido por Mertens (1994).

\section{CONSIDERAÇÕES FINAIS}

Os carboidratos representam entre 70 e $80 \%$ da dieta dos ruminantes e são fundamentais para o atendimento de suas exigências em energia, síntese de proteína microbiana e componentes do leite. As gramíneas forrageiras tropicais apresentam, normalmente, baixos teores de proteína bruta, os quais estão associados a elevados teores de fibra, que pode constituir cerca de $60 \%$ da matéria seca consumida. A fibra representa a fração dos carboidratos de digestão lenta ou indigestível do alimento que ocupa espaço no trato gastrintestinal e, em função de sua concentração e digestibilidade, impõe limitações ao consumo voluntário de matéria seca, minerais e energia. Concentrações mínimas de fibra na dieta que permitam manter a atividade de mastigação, salivação e motilidade do rúmen são fundamentais para assegurar uma perfeita saúde dos ruminantes. A suplementação energética e/ou protéica pode suprir as necessidades em energia e proteína dos microrganismos e do ruminante, proporcionando condições favoráveis ao ambiente ruminal, maximizando o crescimento microbiano e a utilização dos compostos fibrosos da forragem. A sincronização entre as fontes de carboidratos e as de $\mathrm{N}$ maximiza a eficiência microbiana e a diminuição da perda de $\mathrm{N}$ em forma de amônia e da energia dos carboidratos, promovendo melhoria na digestão da MS e, especialmente, da fração fibrosa da forragem.

\section{BIBLIOGRAFIA}

Allen, M.S. 2000. Effects of diet on short-term regulation of feed intake by lactating dairy cattle. J Dairy Sci, 83: 1598-1627.

Allen, M.S. 1996. Physical constrains on voluntary intake of forages by ruminants. J Anim Sci, 74: 3063-3075.

Arroquy, J.I.; Cochran, R.C. e Nagaraja, T.G. 2005. Effect of types of non-fiber carbohydrate on in vitro forage fiber digestion of low-quality grass hay. Anim Feed Sci Technol, 120: 93-106.

Arroquy, J.I.; Cochran, R.C. e Villarreal, M. 2004. Effect of level of rumen degradable protein and type of supplemental non-fiber carbohydrate on intake and digestion of low-quality grass hay by beef cattle. Anim Feed Sci Techno, 115: 83-99.

Baroni, C.E.C.; Lana, R.P. e Mancio, A.B. 2010 a. Consumo e digestibilidade de nutrientes em novilhos suplementados e terminados em pasto, na seca. Arq Bras Med Vet Zoo, 62: 365-372.

Baroni, C.E.C.; Lana, R.P. e Mancio, A.B. 2010b. Desempenho de novilhos suplementados e terminados em pasto, na seca, e avaliação do pasto. Arq Bras Med Vet Zoo, 62: 373-381.

Benez, A.L.C. 2007. Parâmetros ruminais e consumo voluntário de feno de Brachiaria decumbens Stapf. Por bovinos recebendo suplementação protéico-energética. (Dissertação de Mestrado). Universidade Nacional de Brasília.

Berchielli, T.T.; Soares, J.P.G. e Aroeira, L.J.M. 2001. Estimativas da ingestão voluntária a partir das características de degradação do capim-coast-cross (Cynodon dactylon L. Pers.) sob pastejo, por vacas em lactação. Rev Bras Zootecn, 30: 1332-1339. 
Bonhert, D.W.; Schauer, C.S. e Delcurto, T. 2002. Influence of rumen protein degradability and supplementation frequency on performance and nitrogen use in ruminants consuming low-quality forage: cow performance and efficiency of nitrogen use in weathers. J Anim Sci, 80: 1629-1637.

Branco, R.H.; Rodrigues, M.T. e Silva, M.M.C. 2010. Efeito dos níveis de fibra da forragem sobre o consumo, a produção e a eficiência de utilização de nutrientes em cabras lactantes. Rev Bras Zootecn, 39: 2477-2485.

Cabral, L.S.; Valadares Filho, S.; Detmann, E.; Zervoudarkis, J.T.; Pereira, O.G. e Pereira, E.S. 2002. Cinética ruminal das frações de carboidratos, produção de gás, digestibilidade in vitro da matéria seca e NDT estimado da silagem de milho com diferentes proporções de grãos. Rev Bras Zootecn, 31: 2332-2339.

Caldas Neto, S.F.; Zeoula, L.M. e Prado, I.N. 2008. Proteína degradável no rúmen na dieta de bovinos: digestibilidades total e parcial dos nutrientes e parâmetros ruminais. Rev Bras Zootecn, 37: 1094-1 102.

Campling, R.C. e Freer, M. 1966. Factors affecting the voluntary intake of food by cows. 8. Experiments with ground, pelleted roughages. Brit J Nutrit, 16: 507-518

Caton, J.S. e Dhuyvetter, D.V. 1997. Influence of energy supplementation on grazing ruminants: requirements and responses. J Anim Sci, 75: 533-542.

Cheng, K.J. e Hironaka, R. 1973. Influence of feed particles size on $\mathrm{pH}$, carbohydrate content and viscosity of rumen fluid. Can J Anim Sci, 53: 412-422.

Chesson, A. e Forsberg, C.W. 1988. Polysaccharide degradation by rumen microorganisms. In: Hobson, P.N. The rumen microbial ecosystem. Elsevier Applied Science. New York. pp. 251-284.

Church, D.C. 1990. The ruminant animal: digestive physiology and nutrition. Englewood Cliffs. London. 564 pp.

Costa, V.A.C.; Detmann, E.; Valadares Filho, S.C.; Paulino, M.F.; Henriques, L.T. e Mantovani, H.C. 2008. Degradação in vitro da fibra em detergente neutro de forragem tropical de baixa qualidade em função da suplementação com proteína e/ou carboidratos. Rev Bras Zootecn, 37: 494-503.

Costa, V.A.C.; Detmann, E.; Valadares Filho, S.C.; Paulino, M.F.; Henriques, L.T. e Mantovani, H.C. 2009. Degradação in vitro da fibra em detergente neutro de forragem tropical de alta qualidade em função da suplementação com proteína e/ou carboidratos. Rev Bras Zootecn, 38: 1803-1811.

Cullen, A.J.; Harmon, D.L. e Nagaraja, T.G. 1986. In vitro fermentation of sugars, grains, and by-products feeds in relation to initiation ruminal lactate production. J Dairy Sci, 69: 2616-2621.

Detmann, E.; Paulino, M.F. e Valadares Filho, S.C. 2008. Avaliação nutricional de alimentos ou de dietas? Uma abordagem conceitual. Simpósio de Produção de Gado de Corte, 6. 2008. Viçosa. Anais... Universidade Federal de Viçosa. Viçosa. pp. 21-51.

Detmann, E.; Queiroz, A.C. e Cecon, P.R. 2003. Consumo de fibra em detergente neutro por bovinos em confinamento. Rev Bras Zootecn, 32: 1763-1777.

Detmann, E.; Paulino, M.F. e Zervoudakis, J.T. 2004. Níveis de proteína bruta em suplementos múltiplos para terminação de novilhos mestiço em pastejo durante a época seca: desempenho produtivo e característica de carcaça. Rev Bras Zootecn, 33: 169-180.

Detmann, E.; Paulino, M.F. e Valadares Filho, S.C. 2005. Níveis de proteína bruta em suplementos para terminação de bovinos em pastejo durante o período de transição seca/águas: digestibilidade aparente e parâmetros do metabolismo ruminal e compostos nitrogenados. Rev Bras Zootecn, 34: 1380-1391.

Dixon, R.M. e Stockdale, C.R. 1999. Associative effects between forages and grains: consequences for feed utilization. Aust J Agric Res, 50: 757-773.

Dutra, A.R.; Queiroz, A.C. e Pereira, J.C. 1997. Efeito dos níveis de fibra e das fontes de proteína sobre a síntese de compostos nitrogenados microbianos em novilhos. Rev Bras Zootecn, 26: 797-805.
Ekinci, C. e Broderick, G.A. 1997. Effect of processing high moisture ear corn on ruminal fermentation and milk yield. J Dairy Sci, 80: 3298-3307.

El-Shazly, K.; Dehority, B.A. e Jonhson, R.R. 1961. Effect of starch on the digestion of cellulose in vitro and in vivo by rumen microorganisms. J Anim Sci, 20: 268-273.

Forbes, J.M. 1995. Voluntary food intake and diet selection in farm animals. Wallingford. CAB International. Wallingford. $532 \mathrm{pp}$.

Forbes, J.M. e France, J. 1993. Quantitative aspects of ruminant digestion and metabolism. CAB International. Wallingford. $515 \mathrm{pp}$.

Franco, G.L.; Andrade, P.; Bruno Filho, J.R. e Diogo, J.M.S. 2002. Parâmetros ruminais e desaparecimento da FDN da forragem em bovinos suplementados em pastagens na estação das águas. Rev Bras Zootecn, 31: 2340-2349.

Fregadolli, F.L.; Zeoula, L.M. e Prado, I.N. 2001. Efeito das fontes de amido e nitrogênio de diferentes degradabilidades ruminais. 1. Digestibilidades parcial e total. Rev Bras Zootecn, 30: 858-869.

Goetsch, A.L.; Johnson, Z.B. e Galloway, D.L. 1991. Relationships of body weight, forage composition, and supplementation to feed intake and digestion by Holstein steer calves consuming bermudagrass hay ad libitum. J Anim Sci, 69: 2634-2645.

Grant, R.J. 1994. Influence of corn and sorghum starch on the in vitro kinetics of forage fiber digestion. J Dairy Sci, 77: 1563-1569.

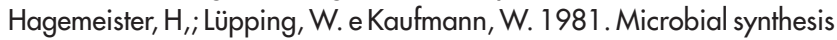
and digestion in the high-yielding dairy cow. In: Haresign, W. (Ed.) Recent advances in animal nutrition. Butterworths. London. pp. 31-48. Hoover, W.H. 1993. Chemical factors involved in ruminal fiber digestion. J Dairy Sci, 71: 522-529.

Huhtanen, P. 1987. The effects of intraruminal infusions of sucrose and xylose on the nitrogen and fiber digestion in cattle receiving diets of grass silage and barley. J Agric Sci Finland, 59: 405-424.

Ishler, V.; Heinrichs, J. e Varga, G. 1996. From feed to milk: understanding rumen function. Willard Building. Penn State Cooperative Extension. (Extension Circular, 422). 52 pp.

Klopfenstein, T. 1996. Need for escape protein by grazing cattle. Anim Feed Sci Technol, 60: 191-199.

Ladeira, M.M.; Valadares Filho, S.C. e Silva, J.F.C. 1999. Consumo e digestibilidades aparentes totais e parciais de dietas contendo diferentes níveis de concentrados, em novilhos Nelore. Rev Bras Zootecn, 28: 395-403.

Lazzarini, I. 2007. Consumo, digestibilidade e dinâmicas de trânsito e degradação da fibra em detergente neutro em bovinos alimentados com forragem tropical, de baixa qualidade e compostos nitrogenados. (Dissertação de Mestrado). Universidade Federal de Viçosa. Viçosa. 52 pp.

Leng, R.A. 1990. Factors affecting the utilization of poor-quality forages by ruminants particularly under tropical conditions. Nutrit Res Review, 3: 277-303.

Lopes, L.S.; Machado Neto, O.R. eAlves, M.C.L. 2010. Efeito de diferentes formas de processamento da ureia na degradabilidade do feno de Coast Cross (Cynodon dactylon) através da técnica de produção de gás. Pubvet, 4: Art\#832.

McCarthy Junior, R.D.; Klusmeyer, T.H. e Vicini, J.L. 1989. Effects of source of protein and carboydrate on ruminal fermentation and passage of nutrients to the small intestine of lactating cows. J Anim Sci, 70: 2002-2009.

Mertens, D.R. 1994. Regulation of forage intake. In: Fahey Junior, G.C. (Ed.) Forage quality, evaluation and utilization. American Society of Agronomy. Madison. pp. 450-493

Mertens, D.R. e Loften, J.R. 1980. The effect of starch on forage fiber digestion kinetics in vitro. J Dairy Sci, 63: 1437-1446.

Miller, B.G. e Muntifering, R.B. 1985. Effect of forage on kinetics of forage fiber digestion in vivo. J Dairy Sci, 68: 4044-4046.

Moraes, E.H.B.K. 2006. Desempenho e exigências de energia, proteína e minerais de bovinos de corte em pastejo, submetidos a diferentes estratégias de suplementação. (Tese de Doutorado em Zootecnia). Universidade Federal de Viçosa. Viçosa. 97 pp. 
Mould, F.L.; Ørskov, E.R. e Mann, S.O. 1983. Associative effects of mixed feeds. I. Effects of type and level of supplementation and the influence of rumen fluid $\mathrm{pH}$ on cellulolysis in vivo and dry matter digestion of various roughages. Anim Feed Sci Technol, 10: 15-25.

Muniz, E.B.; Mizubiti, I.Y.; Pereira, E.S.; Pimentel, P.G.; Ribeiro, E.L.A. e Pinto, A.P. 2012. Cinética ruminal da fração fibrosa de volumosos para ruminantes. Rev Ciência Agron, 43: 604-610.

Nocek, J.E. e Russell, J.B. 1988. Protein and energy as an integrated system. Relationship of ruminal protein and carbohydrate availability to microbial synthesis and milk production. J Dairy Sci, 71: 2070-2107.

Oba, M. e Allen, M.S. 1999. Evaluation of the importance of the digestibility of neutral detergent fiber from forage: Effects on dry matter intake and milk yield of dairy cows. J Dairy Sci, 82: 589-596.

Oliveira, E.R.; Monção, F.P.; Góes, R.H.T.B; Gabriel, A.M.A.; Moura, L.V.; Lempp, B.; Graciano, D.E. e Tochetto, A.T.A. 2013. Degradação ruminal da fibra em detergente neutro de gramíneas do gênero Cynodon spp em quatro idades de corte. Rev Agrarian, 6: 205-214.

Oliveira Júnior, R.C.; Pires, A.V. e Susin, I. 2004. Digestibilidade de nutrientes em dietas de bovinos contendo uréia ou amiréia em substituição ao farelo de soja. Pesq Agrop Bras, 39: 173-178.

Obara, Y.; Dellow, D.W. e Nolan, J.V. 1991. The influence of energy-rich supplements on nitrogen kinetics in ruminants. In: Tsuda, T.; Sasaki, Y. e Kawashima, R. (Eds.) Physiological aspects of digestion and metabolism in ruminants. Academic Press. New York. pp. 515-539.

Ørskov, E.R. 1999. Supplement strategies for ruminants and management of feeding to maximize utilization of roughages. Prevent Vet Med, 38: 179-185.

Paulino, M.F.; Detmann, E. e Valadares Filho, S.C. 2006. Suplementação animal em pasto: energética ou protéica? In: Simpósio sobre Manejo Estratégico da Pastagem, 3, 2006, Viçosa. Anais... Universidade Federal de Viçosa. Viçosa. pp. 359-392.

Poppi, D.P. e McLennan, S.R. 1995. Protein and energy utilization by ruminants at pasture. J Anim Sci, 73: 278-290.

Reis, R.A.; Rodrigues, L.R.A. e Pereira, J.R.A. 1997. A suplementação como estratégia de manejo da pastagem. In: Simpósio sobre Manejo da Pastagem, 13. 1997. Piracicaba. Anais... FEALQ. Piracicaba. pp.123-150.

Rocha, T.C. 2010. Raspa de mandioca na suplementação de novilhos de corte: desempenho, síntese microbiana e caracterização bromatológica. (Dissertação de Mestrado). Universidade Estadual Norte Fluminense. Campos de Goytacazes. 66 pp.

Romney, D.L. e Gill, M. 2000. Intake of forages. In: Givens, D.I.; Owen, E.; Axford, R.F.E. e Omed, H.M. (Eds.) Forage evaluation in ruminant nutrition. CAB. London. pp. 43-62.

Rooke, J.A; Lee, N.H. e Armstrong, D.G. 1987. The effects of intraruminal infusions of urea, casein, glucose syrup and a mixture of glucose syrup and casein on nitrogen digestion in the rumen of catlle receiving grass silage diets. Brit J Nutrit, 57: 89-98.

Russell, J.B. 2002. Rumen microbiology and its role in ruminant nutrition. James B. Russell. Ithaca. $119 \mathrm{pp}$.

Russell, J.B. 1998. Strategies that ruminal bacteria use to handle excess carbohydrate. J Anim Sci, 76: 1955-1963.

Russell, J.B.; O'Connor, J.D. e Fox, D.G. 1992. A net carbohydrate and protein system for evaluating cattle diets. I. Ruminal fermentation. J Anim Sci, 70: 3551-3561.

Russell, J.B. e Wilson, D.B. 1996. Why are ruminal cellulolytic bacteria unable to digest cellulose at low pH? J Dairy Sci, 79: 1503-1509.
Sampaio, C.B.; Detmann, E. e Lazzarini, I. 2009. Rumen dynamics of neutral detergent fiber in cattle fed low-quality tropical forage and supplemented with nitrogenous compounds. Rev Bras Zootecn, 38 : 560-569.

Satter, L.D. e Roffler, R.E. 1979. Nitrogen requeriment and utilization in dairy cattle. J Dairy Sci, 62: 237-245.

Siebert, B.D. e Hunter, R.A. 1982. Supplementary feeding of grazin animals. In: Hacker, J.B. (Ed.). Nutritional limits to animal production from pasture. Commonwealth Agricultural Bureau. Farnham Royal. pp. 409-425.

Silva, D.C.; Alves, A.A.; Lacerda, M.S.B; Moreira Filho, M.A.; Oliveira, M.E e Lafayette, E.A. 2014. Valor nutritivo do capim-andropogon em quatro idades de rebrota em período chuvoso. Rev Bras Saúde Prod Anim, 15; 626-636.

Silva, E.A.; Berchielli, T.T. e Reis, R.A. 2007. Teores de proteína bruta para bovinos alimentados com feno de tifton 85 : consumo e digestibilidades total e parcial. Rev Bras Zootecn, 36: 237-245.

Silva, C.V.; Lana, R.P. e Campos, J.M.S. 2009. Consumo, digestibilidade aparente dos nutrientes e desempenho de vacas leiteiras em pastejo com dietas com diversos níveis de concentrado e proteína bruta. Rev Bras Zootecn, 38: 1372-1380.

Silveira, A.L.F. 2002. Avaliação nutricional da adição de uréia ao feno suplementado com milho moído. (Dissertação de Mestrado). Universidade Federal do Rio Grande do Sul. Porto Alegre. 78 pp.

Souza, M.A. 2007. Consumo, digestibilidade e dinâmica ruminal em bovinos alimentados com forragem tropical, de baixa qualidade e suplementados com compostos nitrogenados e/ou carboidratos. (Dissertação de Mestrado). Universidade Federal de Viçosa. Viçosa. 45 pp.

Tamminga, S.; Van Vuuren, A.M. e Van Der Koelen, C.J. 1990. Ruminal behavior of structural carbohydrates and crude protein from concentrate ingredients in dairy cows. Netherland J Agric Sci, 38: 513-526.

Thiago, L.R.L.S. 1999. Suplementação de bovinos em pastejo: aspectos práticos para o seu uso na mantença ou ganho de peso. In: Encontro de tecnologias para a Pecuária de Corte. 11. 1999. Campo Grande. Anais... Sindicato Rural de Campo Grande. Campo Grande. 23 pp.

Thornton, R.F. e Minson, D.J. 1972. The relationship between voluntary intake and mean apparent retention time in the rumen. Aust J Agric Res, 23: 871-877.

Van Soest, P.J. 1994. Nutritional ecology of the ruminant. 2 Ed. Cornell University. Ithaca. $476 \mathrm{pp}$.

Valadares Filho, S.C. e Pina, D.S. 2006. Fermentação ruminal. In: Berchielli, T.T. (Ed.). Nutrição de ruminantes. FUNEP. Jaboticabal. pp.151-182.

Varga, G.A.; Dann, H.M. e Ishler, V.A. 1998. The use of fiber concentrations for formulation. J Dairy Sci, 81: 3063-3074.

Varga, G.A. e Kononoff, P. 1999. Dairy ration using structural and nonstructural carbohydrates: from theory to practice. In: Southwest Nutrition and Management Conference. Arizona. Proceedings... University of Arizona. Arizona. pp. 77-90. 
